\title{
Double clear plastic screens to minimize droplet spread and aerosolization at extubation in COVID-19 patient
}

\author{
Faisal Shamim, FCPS, Khalid Samad, FCPS, Muhammad Faisal Khan, FCPS \\ Affiliation: Department of Anesthesiology, Aga Khan University Hospital, Karachi, Pakistan \\ Correspondence: Dr. Faisal Shamim, Department of Anaesthesiology, Old Private Wing, Second Floor, Aga Khan University, P.O. \\ Box 3500, Stadium Road, Karachi - 74800, Pakistan. Phone: +922134864639; E-mail: faisal.shamim@aku.edu
}

Citation: Shamim F, Samad K, Khan MF. Double clear plastic screens to minimize droplet spread and aerosolization at extubation in COVID-19 patient. Anaesth. pain intensive care 2020;24(6):696-697; DOI: 10.35975/apic.v24i6.1411

Received: 29 October 2020-, Reviewed: 12 November 2020, Accepted: 15 November 2020

The droplets of novel coronavirus disease 2019 (COVID-19) can be transmitted during aerosolgenerating procedures involving tracheal intubation. ${ }^{1}$ Anesthesiologists are exposed to a higher risk than other specialty healthcare workers because they manage the airway and ventilation. ${ }^{2}$ Extubation is as high a risk for aerosolization of respiratory secretions

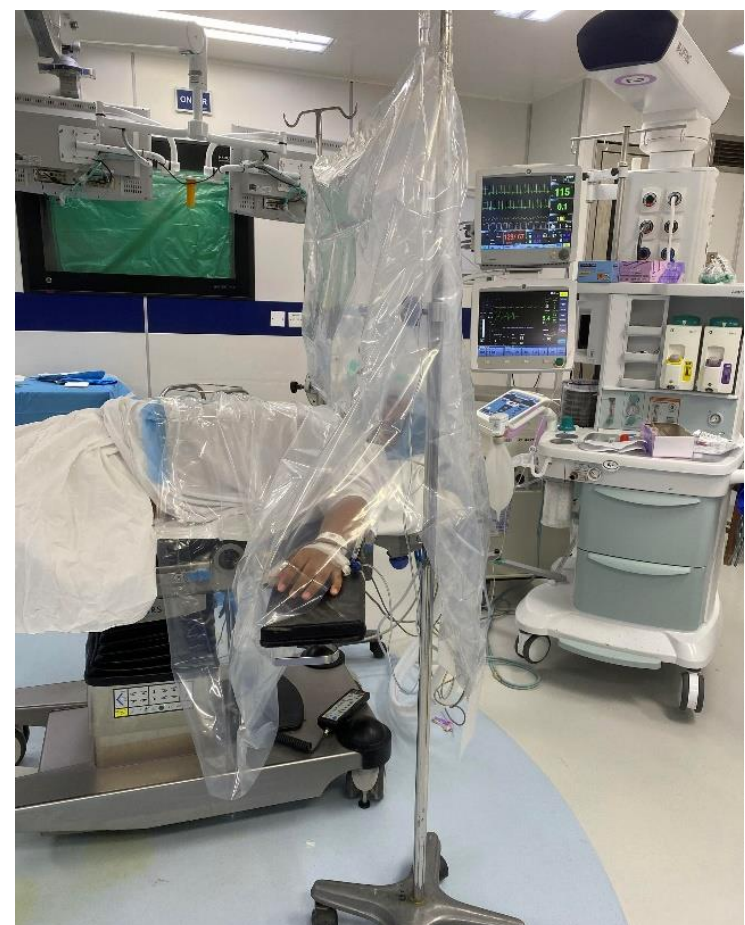

Figure 1: Use of double clear plastic sheets during extubation as is intubation. Additional barriers have been described for intubation like using intubation box or clear plastic drapes but limited options have been explored for extubation. ${ }^{3}$ Some experts suggest placing wet gauze over the patient's mouth and nose just prior to extubation if the patient starts to cough, and/or covering the patient's face with a clear plastic drape. ${ }^{4}$

Recently, a confirmed COVID-19 patient came for appendectomy in which we have used an alternative approach to protect against aerosolized droplets during extubation. Before induction of anesthesia, we put a large clear plastic sheet $(120 \times 200 \mathrm{~cm})$, which is routinely used in pediatric surgery. The screen is adjusted in height and width with two infusion poles (drip stands) to the head end. We intubated with a videolaryngoscope, making sure that the plastic screen acted as a barrier between us and the patient. After draping the surgical site, the pediatric surgeon put another sterile clear plastic sheet over the previous one (Figure 1).

This way, the patient's head and both arms were between two screens, separating them from both the anesthetic and surgical sides. We took advantage to use it at extubation. Before emergence, we made the screens stick at their bottom, so that there was very little leak. There was only space created to put one hand under the anesthetic side of screen for taking out endotracheal tube at extubation. The patient became conscious and extubated after fulfilling the criteria. He 
had had one to two bouts of coughing but we assume that the droplets remained inside this created triangular space made by two screens which were stuck to each other above. The two screens were jointly removed from both poles and rolled over each other

The inexpensive and simple method of using two clear plastic screens during extubation of COVID-19 patients may be considered as an additional barrier. One limitation of this method is that the patient might become irritable or claustrophobic by waking up under the screens that might hamper his sight to look clearly. In resource limited countries where personal protective equipment supplies are scarce and only used for confirmed patients, this method can be used for suspected patients. The cost of one screen is PKR 700, equivalent to $£ 3.64$ or US\$ 4.40 .

\section{Conflict of interest}

No conflicts of interest declared.

\section{Research Quality and Ethics Statement}

The authors of this manuscript declare that this scientific work complies with reporting quality, formatting and reproducibility guidelines set forth by the EQUATOR Network.

\section{References}

1. Odor PM, Neun M, Bampoe S, Clark S, Heaton D, Hoogenboom EM, et al. Anaesthesia and COVID-19 :infection control. Br J Anaesth. 2020 Jul;125(1):16-24 [PubMed] DOI: 10.1016/j.bja.2020.03.025

2. Chen X, Liu Y, Gong Y, Guo X, Zuo M, Li J, et al. Perioperative Management of Patients Infected with the Novel Coronavirus: Recommendation from the Joint Task Force of the Chinese Society of Anesthesiology and the Chinese Association of Anesthesiologists. Anesthesiology. 2020 Jun;132(6):1307-1316. [PubMed] DOI: 10.1097/ALN.0000000000003301

3. Yang YL, Huang $\mathrm{CH}$, Luk HN, Tsai PB. Adaptation to the Plastic Barrier Sheet to Facilitate Intubation During the COVID-19 Pandemic. Anesth Analg. 2020 Aug;131(2):e97-e99. [PubMed] DOI: 10.1213/ANE.0000000000004923

4. Zuo MZ, Huang YG, Ma WH, Xue ZG, Zhang JQ, Gong $\mathrm{YH}$, Che L; Chinese Society of Anesthesiology Task Force on Airway Management, Airway Management Chinese Society of Anesthesiology Task Force on. Expert Recommendations for Tracheal Intubation in Critically ill Patients with Noval Coronavirus Disease 2019. hin Med Sci J. 2020 Feb 27;35(2):105-9. [PubMed] DOI: 10.24920/003724 